\title{
RISKS OF INDUSTRY 4.0 AND DIGITIZATION
}

\author{
Beatrix FREGAN ${ }^{1}$, István KOCSIS ${ }^{2}$, Zoltán RAJNAI ${ }^{3}$ \\ ${ }^{1}$ National University of Public Service, Budapest, Hungary, fregan.beatrix@uni-nke.hu \\ ${ }^{2}$ Obuda University, Doctoral School on Safety and Security Sciences, Budapest, Hungary \\ kocsis.istvan@phd.uni-obuda.hu \\ ${ }^{3}$ Obuda University, Doctoral School on Safety and Security Sciences, Budapest, Hungary \\ rajnai.zoltan@bgk.uni-obuda.hu
}

\begin{abstract}
Industry 4.0 is considered as the digital transformation of manufacturing. Changes due to digitalization are running at a continuously accelerating speed, developments change our whole world, and completely changing the production and labor markets. An overview of the labor market effect of overall digitalization is provided. Predictions and forecasts for labor market phenomena due to robotization are given in terms of overall changes in employment. Changes in employment structure are influenced by several factors of computerizability of the individual work activities of various jobs.
\end{abstract}

Keywords: Industry 4.0, digitalization, automation, robotization, artificial intelligence, human resources, labor market, education.

\section{Introduction}

Industry 4.0 and digitalization penetrate, though at a varying pace, into all branches, and fields of the economy. They thus have a growing effect on the labor market and an increasing influence on future workplaces in developed economies. It is expected, that the "fourth industrial revolution" would bring a complete change of manufacturing and a total transformation of the entire economy.

A major share of human employment and types of jobs can be endangered. However, new technology, new methods, processes, new business models based on new, creative products, and services could create new employment opportunities, including requirements for new types of jobs. Changes in competitiveness and various rates of economic development of countries could create economic gaps, social imbalances, and tension within society.

Digitalization is characterized by rapid development including disruptive and innovative changes. No previous experience is present concerning opportunities based on new enabling technologies, emerging artificial intelligence, and new or- ganizational methods. Models, and rules undergo huge, unforeseen changes, consideration is taken into account might be effect influenced by stakeholder interests or expectations. Thus, making forecasts for the future seems not to be realistic.

According to the traditional pattern, development of industrial productivity due to automation leading to losses of jobs was neutralized by increasing volumes of production. Having achieved a market saturation, cost reduction was deemed to be the right measure for maintaining competitiveness. A significant share of production has been relocated to low-wage countries causing a decrease in European employment. At a current GDP-share of $15 \%$ of industrial production in Western Europe, approximately 5 million industrial jobs have been lost in the recent 15 years [1].

\section{Labor Market Effects of Overall Digitalization}

Current digital technologies make it possible, and the requirement for being competitive makes it inevitable to have a huge amount of information present practically in milliseconds globally 
for all stake-holders. The global landscape results in an intensified competition. Development processes are continuously accelerating, time-tomarket cycles are shortened. Even minor differences in current knowledge, and technology level could accumulate to huge divergences of competitiveness in a relatively short time, rearranging various aspects of our current world.

Countries and regions adopting new technology faster, and having a strong background in the fields of new enabling technologies are candidates for being a forerunner of the future. Robotics is considered as a key enabling field of technology. Similar factors and future trends apply in various contexts: at the branch, profession, company, and individual levels [2].

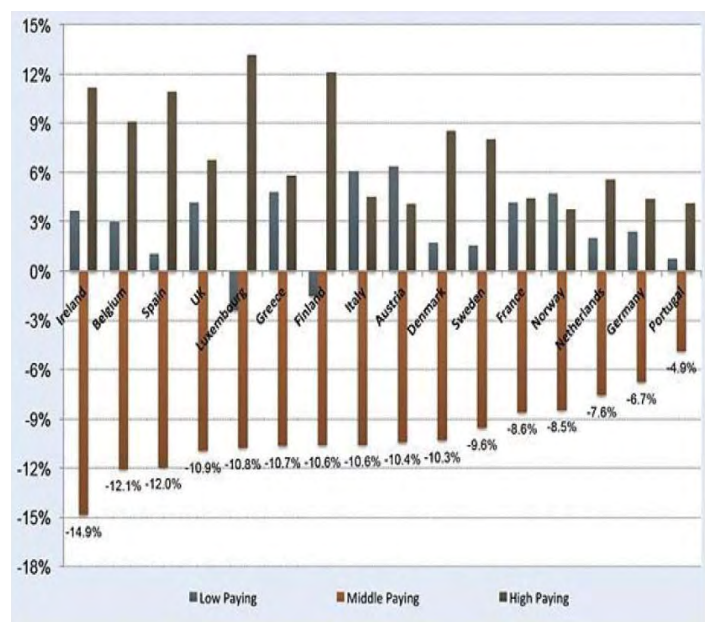

Figure 1. Change in employment shares in low, middle and high payed segments in $16 \mathrm{EU}$ member states between 1993, and 2010 show a polarization of the labor market: increasing employment in low and high wage, and a decrease in the middle wage segments

\section{Forecasts}

According to statistics of recent decades, polarization is present in the labor market. Employment has been increased in low and high wage segments of employees, and a decrease in the middle wage segments [3]. People with special skills are hard to substitute and can achieve a higher income. People with lower education or less up-to-date skills do jobs which can be done by most of the people, but their labor costs are much lower.

As a consequence, a similar polarization is in progress and predicted for future demand on the US labor market for various levels of education
[4]. Demand for a highly educated (BSc, MSc, and $\mathrm{PhD}$ ) workforce is growing, demand at medium levels is stagnating.

Experts have set up models, lead surveys to predict the overall effects of digitalization on the labor market. According to a study of the EU Commission DG for Internal Policies [5]. Factors for creating new jobs include Development of new products, machines and increased competitiveness creating new jobs. Increased productivity, substitution of the human workforce, relocation and outsourcing of jobs to emerging countries, and offshoring could all lead to losses of jobs. Cedefop predicts the creation of 8.5 million knowledge-intensive, and 2 million elementary jobs. 4 million skilled manual jobs would be lost.

The Roland Berger Consultants, based on an adoption rate of "Industry 4.0 solutions" of $50 \%$, and 25 million employees, taking various factors into account, draw a small positive balance of industrial employment by 2035 in Germany [1].

BCG, modelling the German industrial employment, assuming various additional revenue scenarios resulted by Industry 4.0, the total change of a number of jobs could be between a decrease of 1.8 million and an increase of 6.0 million by 2025 [6].

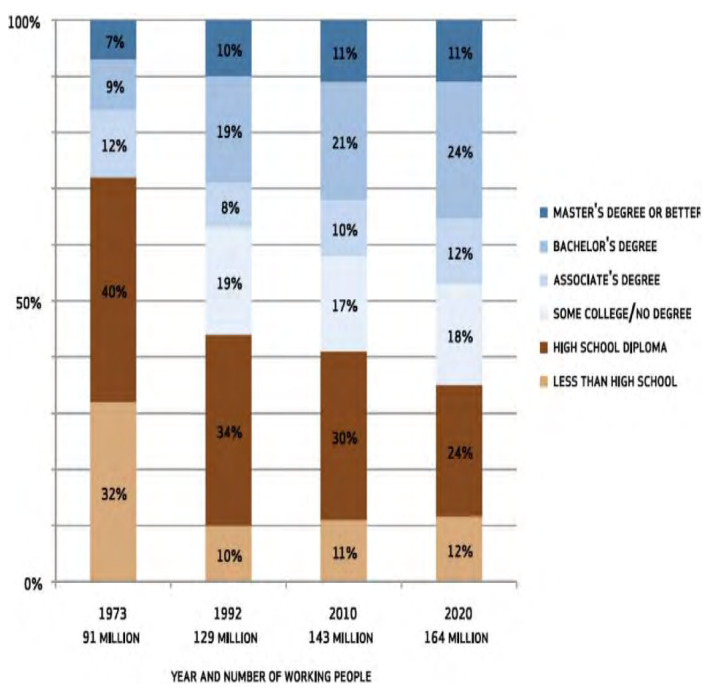

Figure 2. Predictions of qualification demand by 2020 in the US labor market: a defitive growth of the demand for higher educated profesionals (BSc, MSc, PhD) is forecasted

The Oxford Martin Programme surveys in the US have set up a list of computerizable probabilities of 702 jobs. According to the overall conclusion, $47 \%$ of total US employment is endangered by computerization in the next $10-20$ years [6]. 


\section{Current and Predicted Effects of Robotization}

Major bottlenecks for computerization and robotization of jobs at the current technology level are perception and manipulation; creative Intelligence (e.g. originality, fine arts); social intelligence (e.g. perceptiveness, negotiation skills, cooperation with others), according.

According to McKinsey, analyzing 800 occupations and 2000 work activities for assessing their potential for automation, only a small percentage of occupations can be fully automated using current technologies, but some of the work activities in all occupations could be automated. It is predicted, that occupational structure would change. Along with the development of physical and mental capabilities of machines, significant growth of not only machine to machine but man to machine interactions is expected. Candidate fields for increased employment demands are R\&D, human interface design, IT and data integration, logistics, robotics and automation.

New occupations or roles would emerge: industrial data scientist, robot coordinator are examples. Current results of analyses show that new employment is created in logistics - partially because of outsourcing; services; and new applications - using technology developed to create new products. The jobs require more advanced manufacturing and communication skills, human tasks are becoming more complex.

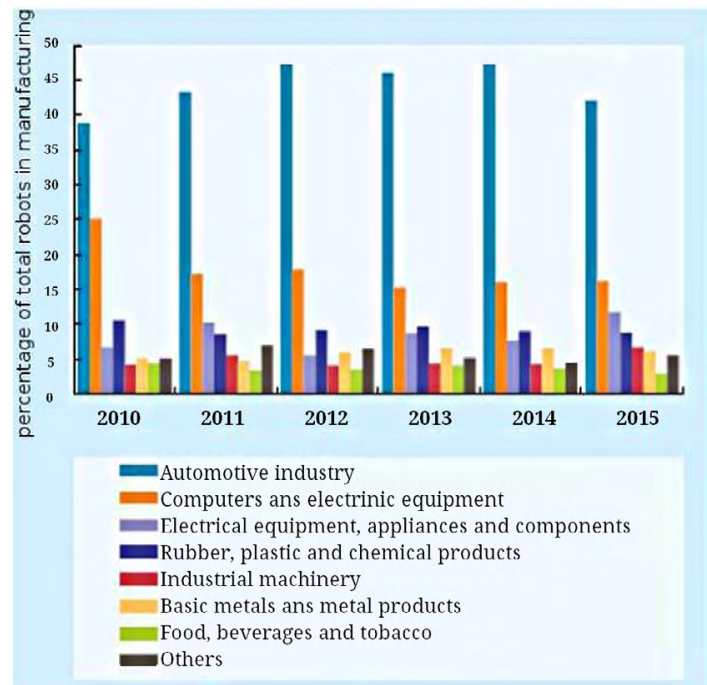

Figure 3. Indistrial Robots global annual installation by manufacturing sector 2010-2015

\subsection{After 2030's}

BCG predicts that the growth rate of the number of installed advanced robots globally would increase from the current 2-3 percent to 10 percent yearly, in the next decade. Adoption rates will vary over a wide range. Robot systems are traditionally expensive. Eighty percent of robots are installed in five countries only (China, Germany, Japan, Korea, US), and are concentrated in large companies. Some countries such as Indonesia, Korea, Taiwan, and Thailand introduce robotics more aggressively. By 2025, in these countries, half of the tasks could be performed by robots. In 15-20 years a market saturation could be reached. In the most affected ten to twelve countries labor cost reduction due to robotization could be between 15, and 30 percent, while having lower effects in other countries. This effect will contribute to the increasing imbalances in economic competitiveness.

\section{Conclusion}

Industry 4.0, digitalization in future manufacturing presents fast, and continuously accelerating changes in production, economy, and society. Developments include disruptive changes in manufacturing in services and make revolutionary new business models possible. A major factor in the changes in manufacturing is robotics. Due to technology development, the performance and versatility of robots are increasing, at the same time robots are becoming more affordable. The application of robotics is reaching its take-off in manufacturing.

According to predictions, a significant share of jobs is at risk due to computerization, and digitization. The process involves loss of jobs, the creation of new jobs, including emerging new job types. Structure of employment and the work environment is changing. This includes higher demand for new human competences and machine capabilities for a massively increased human to machine communication and cooperation.

Markets, investments, factors of competitiveness, and employment could be relocated to other regions. Rearrangement of production factors and revenues between countries and regions continues. With higher investments in knowledge and the newest technology, Industry 4.0 could bring a new model of competitiveness. Development, higher investment into, and adoption of new technologies, including robotics, is a key 
driving factor for increased competitiveness. The result is - in most cases - economic growth and higher employment in specific economies.

Digitalization, automation, and robotization present an opportunity for avoiding high labor costs in developed economies. Production capacities can be repatriated from developing countries. (note: Another factor in repatriation from some developing countries might be less demand for raw materials.) Economies of states enjoying competitiveness based on the low-wage model might be at risk in the future. This may include Hungary, and the CEE countries, which need to find new competitive advantages.

\section{References}

[1] The Industry 4.0 transition quantified. Think Act Beyond the mainstream. Roland Berger $\mathrm{GmbH}$., München, Germany. 2016.
[2] Autor D. H.: Polanyi's Paradox and the Shape of Employment Growth. NBER Working Paper 20485, National Bureau of Economic Research. Inc., Cambridge, MA. 2014. https://doi.org/ 10.3386/w20485

[3] Employment and skills aspects of the Digital Single Market strategy. European Parliament, DG for Internal Policies, 2015.

[4] The Boston Consulting Group: Man and Machine in Industry 4.0 - How will technology transform the industrial workforce through 2025? (accessed Jan. 2018).

https://www.bcg.com/industries/engineered-products-infrastructure/man-machine-industry-4.0.aspx

[5] The future of work: Digitalisation in the US labour market. ISBN 978-92-823-9002-3, European Parliament, DG for Internal Policies, 2016.

[6] Frey C.B., Osborn M.A.: The Future of Employment: How susceptible are jobs to computerisation? (Oxford Martin Programme on Technology and Employment, Oxford University. 2013) 